\title{
Socioeconomic Determinants of Health \\ Contributing to the Consumption of Nonprescribed Medicines in Ethiopia
}

This article was published in the following Dove Press journal: Patient Preference and Adherence

\author{
Elizabeth Woldemariam Teketel \\ University of South Africa, UNISA, \\ Pretoria, South Africa
}

Background: Social determinants of health are understood as the conditions in which people are born, grow, live, work, and age that shapes health and include a domain of factors. Self-medication is influenced by these socioeconomic factors. This study, aims to quantitatively examine the relationship between these factors and the use of nonprescribed medicines and then identify which of the factors have the highest predictable value in Ethiopia.

Methods: A quantitative, descriptive, cross-sectional, community-based research approach was used to explore the relationship between the dependent and independent variables in Addis Ababa, Ethiopia. Descriptive statistics, cross-tabulations, bivariate and regression analysis were used in the analysis.

Results: A total of $72.2 \%(n=433)$ participants were found to have an ever experience of self-medication in their life and $35.7 \%)(n=214)$ have the practice in the last two months. Bivariate analysis showed that in the predisposing factors categories: age group (50-59) ( $p$-value $=0.034)$; those who are knowledgeable about all drugs not to be given to nursing mother $(p$-value $=0.006)$; those who agree on the attitude that they would rather treat themselves than go to the nearest health facility ( $p$-value $=0.000)$ in the enabling factors; those who were satisfied with their financial quality of life $(p$-value $=0.014)$ and from the need factors; those who perceived their health status as good ( $p$-value $=0.000)$ showed a significant association. Multivariate analysis showed that age, knowledge, attitudes showed statistical significance. Also, quality of life satisfaction of enabling factors and illness in the past two months from need factors had a statistically significant effect as predictors of utilization of nonprescribed medicines.

Conclusion: To strategize for appropriate self-medication, interventions should focus on changing the knowledge, attitude, and perception of the specific sociodemographic factors identified in the study.

Keywords: sociodemographic factors, community, Ethiopia, use of nonprescribed medicines

\section{Background}

Social determinants of health (SDH) are understood as the conditions in which people are born, grow, live, work, and age and that shape health and include factors like economic stability, education, health, and health care, the neighborhood and built environment, and the social and community context domain. ${ }^{1}$ Actions on SDH are required to reduce inequalities in health. ${ }^{2}$ The WHO Global Commission on the Social Determinants of Health (CSDH) identified that inequalities in SDH driven by inequalities in power, money, and resources are driving inequities in health. ${ }^{3}$

Correspondence: Elizabeth Woldemariam Teketel

Email elizabethwoldemariam@gmail.com
Patient Preference and Adherence 2021:15 213-226

submit your manuscript (c) (i) (5) 2021 Teketel. This work is published and licensed by Dove Medical Press Limited. The full terms of this license are available at https://www.dovepress.com/terms.php C. you hereby accept the Terms. Non-commercial uses of the work are permitted without any further permission from Dove Medical Press Limited, provided the work is properly attributed. For permission for commercial use of this work, please see paragraphs 4.2 and 5 of our Terms (https://www.dovepress.com/terms.php). 
Self-medication (SM) is a component of self-care, which means the responsible selection and use of nonprescribed medicine that is believed to be safe and effective when used as directed including the intermittent or continued use of a medication prescribed by a physician for chronic or recurring disease or symptoms by individuals to treat self-recognized illness or symptoms. ${ }^{4}$ It entails the use of drugs without the advice, recommendation, prescription, diagnosis, and supervision of physicians, or the use of any drugs without consultation with health care staff, and based on the self-diagnosis of diseases and their symptoms. ${ }^{5}$

Irresponsible SM or the use of nonprescribed medicines without proper medicine information is associated with several challenges. ${ }^{6}$ These include adverse drug reactions, misdiagnosis, use of expired drugs, use of drugs in excessive amounts, prolonged duration of use, drug interactions, a deterioration in health status, the masking of the presence of severe disease, drug interactions, adverse drug reactions, monetary attrition, risk of dependence and abuse, polypharmacy and other toxicological and pharmacological risks..$^{7-9}$ In this regard, the risk of antimicrobial resistance and its public health impact is also an additional issue. ${ }^{10-16}$

On the contrary, SM or the use of nonprescribed medicine is a behavioral response of individuals to promote or restore their health and encourage self-care and has advantages that include saving scarce medical resources, reducing absenteeism from work, reducing pressure on available medical services, and increase availability of health care populations in rural areas. ${ }^{6,17,18}$

Several pieces of evidence have shown that SM practice is influenced by sociodemographic factors, which include level and field of education, economy, job status advertisements, advice from relatives or friends, availability of pharmacies, mobile applications, self-knowledge and previous prescriptions by doctors or experience with a drug to treat similar illness. ${ }^{19-25}$ Hence understanding the socioeconomic characteristics of SM is essential to inform public policy aimed not only at deterring undesirable SM and promoting the quality of responsible $\mathrm{SM}$, but also at promoting equitable access to medical care. ${ }^{26-28}$

Like all the other developed and developing countries, the use of medicines that are not prescribed or SM are being practiced in Ethiopia and the prevalence is evidenced in specific population groups, pregnant mothers ${ }^{29}$ and students ${ }^{30}$ and across different settings studied ranging from $12.8 \%$ to $77.1 \%$.

However, there are no studies in the country that investigated the use of nonprescribed medicines and their relationship with socioeconomic factors. Therefore, the objective of this study is to fill this gap first by examining the relationship between the socioeconomic determinants and the use of nonprescribed medicines and second by identifying which of the factors have the highest predictable value. The findings will contribute to the available body of knowledge about the individual users which will then enable the health-care system to design interventions.

\section{Methods}

A quantitative, descriptive, cross-sectional, communitybased research approach was used to explore the prevalence of the use of nonprescribed medicines in the last two months including their ever use and the predictor effect of socioeconomic factors in a sample of 600 participants selected through multistage sampling method.

The study population is the community of Yeka subcity Addis Ababa, Ethiopia. Inclusion and exclusion criteria were set and those under 18 years of age, that are incapable of hearing and speaking, that have mental health problems, and those who were unwilling to participate were not included in the study.

The sample size was calculated using the single population proportion formula and the $38.6 \%$ average prevalence reported in the systematic review. ${ }^{31}$

$$
n=\frac{\left(Z_{a / 2}\right)^{2} \times P(1-P)}{d^{2}} \times d e
$$

Where $n$ is the sample size; $Z \alpha / 2$ is the standard normal distribution value at the $95 \%$ confidence interval level, which is $1.96 ; P$ is the proportion of $\mathrm{SM},(38.6 \%) ; d$ is the margin of error taken as $5 \%$; de is the design effect for using multistage sampling taken as 1.5 . The final sample size used for the research was 600 households with $10 \%$ considered contingency.

Sampling was carried out in three phases. In phase one of the process, six districts (woredas in local language) were selected by simple random sampling method from the total 14 weredas available in the Yeka sub-city. Those selected were weredas $1,2,3,6,8$, and 12 . In phase two, the sample allocated for each of the six weredas was allocated by distributing the total sample size $(n=600)$ proportionally to the total number of people in each wereda (Table 1). The calculation of the sample allocated to 
Table I Number of Samples Allocated for Each Wereda $(n=600)$

\begin{tabular}{|l|l|l|}
\hline $\begin{array}{l}\text { Number of } \\
\text { Weredas }\end{array}$ & $\begin{array}{l}\text { Total Population } \\
\text { Number }\end{array}$ & $\begin{array}{l}\text { Sample Number } \\
\text { Allocated }\end{array}$ \\
\hline Wereda I & 33,569 & 100 \\
Wereda 2 & 39,340 & 117 \\
Wereda 3 & 19,027 & 56 \\
Wereda 6 & 25,012 & 74 \\
Wereda 8 & 25,650 & 76 \\
Wereda 12 & 59,588 & 177 \\
\hline
\end{tabular}

each wereda was obtained by using the following formula as follows. ${ }^{31,32}$

$$
N=\frac{\text { Number of the population at each wereda }}{\text { Total number of population at the six weredas }} \times 600
$$

In phase three of the sampling process, subjects were selected to participate in the study using the house number of the households, which was obtained from the administrative offices of each wereda, as a sampling frame. Each household was then selected through a systematic random sampling method to be the candidate for the study. The adult participants in the selected household were briefed about the objective of the study, requested for their consent and when they agreed, they were provided with a consent form and their signature was obtained.

Data were collected using a structured interview-based questionnaire which was originally developed for this study based on the conceptual framework for this research as well as the review of the literature. Data collection was carried out in February 2019. Reliability and validity of the data collection tool were ensured through pretest in 30 individuals in the wereda 13 of which were not selected for the actual study, modifications were done based on the result of the pretest. Content validity and construct validity tests were performed using Cronbach's alpha testing method. Data collection tool was also commented by five pharmacists and corrections were made accordingly. Collected data was cleaned before analysis.

Ethical clearance was obtained from the UNISA Health Studies Research Ethics Committee (Ethical clearance number is HSHDC/876/2018 and and from the Addis Ababa Regional Health Bureau Ethics Review Committee for the conduct of the survey. The study was conducted in accordance with the Declaration of Helsinki maintaining ethical principles for medical research on humans.

Data were coded and analyzed using the Statistical Package for Social Sciences (SPSS) version 25. Data analysis included descriptive statistics and crosstabulations. The relationship between the dependent and independent variables was compared using the chi-square $\mathrm{d}$ test and regression analysis. The level of statistical difference was set at $p<0.05$. The hypothesis in the test was the null hypothesis $\left(\mathrm{H}_{0}\right)$ that the predictors/socioeconomic factors did not have any effect on the utilization of nonprescribed medicines.

Regarding the assessment of the knowledge response of the study, a three-scale knowledge category of nonprescribed medicine consumption was established. Respondents were asked to reply (yes or no) to 11 questions. A score of 1 was allocated for every correct answer provided and a score of 0 was allocated for any wrong answer provided or any correct statement left unanswered. During analysis, the summation of the scores in this question item was calculated to a maximum of 11 for each respondent; and plotted on a normal distribution curve to determine the mean

$\left(x_{k}\right)$ knowledge score and standard deviation $\left(s_{k}\right)$. The knowledge of nonprescribed medicines among the respondents was then categorized as "good" for those who lie above $\left(x_{k+} s_{k}\right)$; "average" for those within $\left(x_{k}^{ \pm s_{k}}\right)$; and "poor" for those below $\left(x_{\mathrm{k}}-s_{\mathrm{k}}\right)$ on the normal distribution curve. $^{33,34}$

Respondents' attitude towards SM was assessed using seven statements rated on a Likert grading on a three-point scale which was scored as agree $=1$; neutral $=2$; disagree $=3$. The minimum score obtainable was nine and the maximum 27. The midpoint (18) was used as the cutoff. A score of $0-17$ was graded as negative attitude whereas $\geq 18$ was graded positive attitude. ${ }^{4}$ A similar analysis was used for the perception of the safety of SM items in that, the minimum score obtainable was three and the maximum nine. The midpoint (6) was used as the cutoff. The findings of the empirical data together with the reviewed literature were used to provide recommendations.

The understanding of the effect of socioeconomic factors of health on health-care service utilization (selfmedication/SM in this study) is best explained by Anderson's Behavioural Model and hence the whole research was guided by it. According to Anderson's conceptual framework, an individual's access to and use of health services and health-seeking behavior is considered to be a function of three characteristics: predisposing, enabling, and need factors. ${ }^{35}$ 


\section{Dependent Variable}

For the purpose of this research, SM or the use of nonprescribed medicine was the self-reported treatment of common health problems by the study participants with modern and/or traditional medicines without direct medical or traditional healer supervision or intervention in the past two months before the study. In addition, SM was used interchangeably with the use of nonprescribed medicines throughout the document.

\section{Independent Variable}

The socioeconomic factors of health that were believed to contribute to the health-seeking behavior (self-medication) and investigated were defined as follows:

- Predisposing factors were: age, sex, marital status, knowledge about SM attitude about SM, education, occupation, ethnic religion, SM if you know someone has taken it before, SM if it has been taken before, $\mathrm{SM}$ if the medicine is available at home, having no trust in the health-care service, having an old prescription at home, knowing the name of the medicine to buy, having a similar experience of the illness previously, the influence of family/friends who have taken the medicine before, and having the medicine at home.

- Knowledge on SM (how medications are used and various negative effects of medicines), attitude on SM, and perception on safety.

- Enabling factors: income, employment status, health insurance, and quality of life.

- Need factors: illness in the previous two months, presence of chronic disease, and self-reported health status.

\section{Results and Discussion}

\section{Sociodemographic Characteristics}

A total of 600 respondents from the six woredas participated in this study with a $100 \%$ respondent rate. Table 2 presents the distribution of the respondents by the sociodemographic characteristics.

Respondents aged (30-39) were 28.3\% $(n=170), 81.2 \%$ $(\mathrm{n}=487)$ were female, $62.3 \%(\mathrm{n}=374)$ were married, $79.7 \%$ $(n=478)$ of them were Orthodox Christians, 55\% $(n=330)$ were from Amhara ethnic group and at the time of the survey, the highest educational status attained by the participants was primary school $31.2 \%(n=187)$.
Table 2 Sociodemographic Characteristics of the Respondents $(n=600)$

\begin{tabular}{|c|c|c|}
\hline & Frequency & Percent \\
\hline \multicolumn{3}{|l|}{ Age } \\
\hline $18-29$ & 127 & 21.2 \\
\hline $30-39$ & 170 & 28.3 \\
\hline $40-49$ & 126 & 21 \\
\hline 50-59 & 80 & 13.3 \\
\hline$>60$ & 97 & 16.2 \\
\hline \multicolumn{3}{|l|}{ Gender } \\
\hline Male & 113 & 18.8 \\
\hline Female & 487 & 81.2 \\
\hline \multicolumn{3}{|l|}{ Marital status } \\
\hline Unmarried & 94 & 15.7 \\
\hline Married & 374 & 62.3 \\
\hline Divorced & 51 & 8.5 \\
\hline Widowed & 81 & 13.5 \\
\hline \multicolumn{3}{|l|}{ Highest educational status } \\
\hline No formal education & $|3|$ & 21.8 \\
\hline Primary school & 187 & 31.2 \\
\hline High school & $|4|$ & 23.5 \\
\hline Diploma & 84 & 14.0 \\
\hline Degree & 53 & 8.8 \\
\hline Postgraduate degree & 4 & 0.7 \\
\hline \multicolumn{3}{|l|}{ Family status } \\
\hline I-4 inhabitants & 355 & 59.2 \\
\hline $5-8$ inhabitants & 219 & 36.5 \\
\hline$>9$ inhabitants & 26 & 4.3 \\
\hline \multicolumn{3}{|l|}{ Household responsibility } \\
\hline Mother & 433 & 72.2 \\
\hline Father & 71 & 11.8 \\
\hline Child & 80 & 13.3 \\
\hline Relative & 16 & 2.7 \\
\hline \multicolumn{3}{|l|}{ Health insurance } \\
\hline Community based & 26 & 4.3 \\
\hline Employment based & 38 & 6.3 \\
\hline I have no insurance & 536 & 89.3 \\
\hline \multicolumn{3}{|l|}{ Monthly income (Ethiopian birr) } \\
\hline Low income: $100-2000$ & 288 & 48 \\
\hline Middle income: $200 \mathrm{I}-4000$ & 147 & 24.5 \\
\hline High income: $4000-6000$ & 89 & 14.8 \\
\hline The highest income: $>6000$ & 76 & 12.7 \\
\hline \multicolumn{3}{|l|}{ Ethnicity } \\
\hline Amhara & & 55 \\
\hline Gamo & & 0.2 \\
\hline Gurage & & 7.5 \\
\hline Hadiya & & I \\
\hline Kembata & & 0.2 \\
\hline Oromo & & 22.7 \\
\hline
\end{tabular}

(Continued) 
Table 2 (Continued).

\begin{tabular}{|l|l|l|}
\hline & Frequency & Percent \\
\hline Refused to answer & & 5.8 \\
Sidama & & 0.2 \\
Silte & & 1.2 \\
Tigre & & 5.5 \\
Wolayita & & 0.8 \\
\hline Total & $\mathbf{6 0 0}$ & 100.0 \\
\hline
\end{tabular}

Table 3 Occupational Status of the Respondents $(n=2 \mid 3)$

\begin{tabular}{|l|l|l|}
\hline Occupation & Frequency & Percentage \\
\hline Manager & 14 & 6.6 \\
Professional & 61 & 28.6 \\
Clerical job & 21 & 9.9 \\
Sales and services & 43 & 20.2 \\
Skilled laborer & 41 & 19.2 \\
Unskilled laborer & 33 & 15.5 \\
\hline Total & $\mathbf{2 1 3}$ & 100.0 \\
\hline
\end{tabular}

Regarding family status, $59.2 \%(\mathrm{n}=355)$ of the respondents have 1-4 inhabitants living in the same house. Most of the respondents $72.2 \%(n=433)$ were mothers in their household responsibility. The majority of the participants $89.3 \%(\mathrm{n}=536)$ had no health insurance, $50.7 \%(\mathrm{n}=304)$ were housewives and out of those employed $(n=213)$, $28.6 \%(\mathrm{n}=61)$ were professionals (Table 2) (Table 3) (Figure 1).

The household income of the respondents ranged from Ethiopian birr 100 to 23,000 indicating a wide range between the two extremes of household income. According to Kothari and Garg, ${ }^{33}$ the distribution of the monthly household income of the respondents was asymmetrical and the income distribution were right-skewed

\section{Employment status}

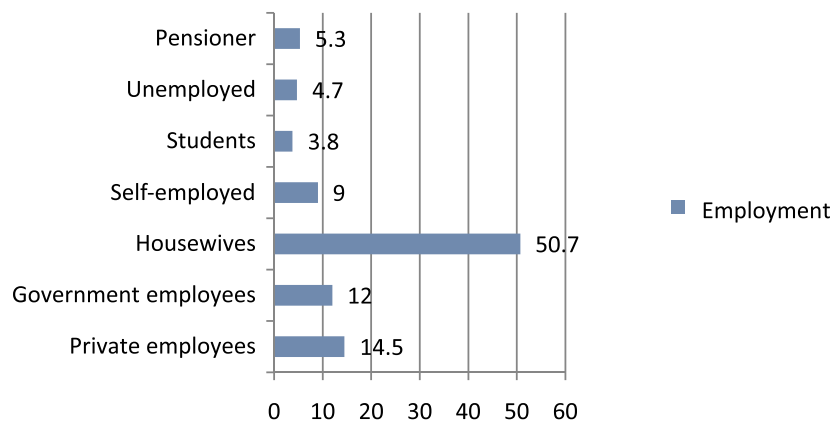

Figure I Bar graph of percentage of employment history of respondents $(n=600)$.
Table 4 Characteristics of the Health Status of the Respondents

\begin{tabular}{|l|l|l|}
\hline & Frequency & Percentage \\
\hline Health Status & & \\
Very good & 267 & 44.5 \\
Good & 173 & 28.8 \\
Average & 135 & 22.5 \\
Poor & 25 & 4.2 \\
\hline Illness in the past two months & & \\
Yes & 263 & 43.8 \\
No & 337 & 5 \\
\hline
\end{tabular}

(coefficient of skewness $=2.045$ ) and has a thin distribution (coefficient of kurtosis $=5.810$ ). The median annual household income was Ethiopian birr 2500. The monthly income of the respondents was divided into four income groups (Table 2). Based on the income grouping, $48 \%$ $(n=288)$ of the respondents were categorized into the lower-income group, $24.5 \%(\mathrm{n}=147)$ in the middle groups and $14.8 \%(\mathrm{n}=89)$ in the high-income group and $12.7 \%$ $(n=76)$ were categorized into the highest income group.

As indicated in Table 4, 44.5\% $(n=267)$ of the respondents were in a very good health status at the time of the survey, $28.8 \%(\mathrm{n}=173)$ in a good health status, $22.5 \%$ $(n=135)$ in average health status and $4.2 \%$ (25) of the participants said that they have poor health status. As to any illness in the past two months, $43.8 \% \quad(n=263)$ responded by saying that they were ill in the past two months before the survey and $56.2 \%(n=337)$ said they were not.

\section{Knowledge of Self-medication}

As described in the methods part, the maximum score of the knowledge was calculated. Out of a total score of 11, the mean score for knowledge of SM among respondents was 8.1 ( $\mathrm{SD} \pm 2.328$ ). In addition, only $16.3 \%$ of the respondents had good knowledge of SM, 70.3\% had average knowledge and $13.3 \%$ had poor knowledge of SM.

In addition, specific questions on knowledge (Table 5) indicated that $61.2 \%(n=367)$ of the participants were not knowledgeable about the type of information that should be available while self-medicating. In contrast, $47.8 \%(n=287)$ were not knowledgeable about the presence of drugs that should not be simultaneously taken with other drugs which is slightly higher than the observations in a recent study ${ }^{36}(37.3 \%)$. This difference could be due to the variation in the study setting and 
Table 5 Description of Specific Questions on Knowledge of Self-medication (SM)

\begin{tabular}{|l|l|l|}
\hline Question & \multicolumn{2}{|l|}{ Knowledge of Respondents (Percentage) } \\
\cline { 2 - 3 } & Knowledgeable & Not Knowledgeable \\
\hline Do you know how to store medicine at home? & 73.8 & 26.2 \\
What type of information should be available during taking SM? & 38.8 & 61.2 \\
There are some drugs that should not be simultaneously taken with other drugs & 52.2 & 47.8 \\
Some drugs cannot be taken with alcoholic drinks. & 96.8 & 3.2 \\
Some drugs cannot be taken with all types of food items. & 73.7 & 26.3 \\
All types of drugs cannot be given to children. & 95.3 & 4.7 \\
All types of drugs cannot be given to pregnant women. & 94.3 & 5.7 \\
All types of drugs cannot be taken by patients having a chronic disease? & 50.2 & 49.8 \\
All types of drugs cannot be taken by nursing mothers & 81.2 & 18.8 \\
Some drugs can be available in different dosage forms & 70.8 & 29.2 \\
The same drug can be a remedy and a poison & 82.7 & 17.3 \\
\hline
\end{tabular}

study population or ample size. Besides, $49.8 \%(\mathrm{n}=299)$ did not know that all types of drugs cannot be taken by patients having a chronic disease. Moreover, 26.3\% $(n=158)$ did not know that some drugs cannot be taken with all types of food items, $26.2 \%(n=157)$ did not have the knowledge on how to store medicines at home, and $18.8 \%(\mathrm{n}=113)$ of the respondents did not know that all types of drugs cannot be taken by nursing mothers.

\section{Attitude on Self-medication}

Most of the respondents have a generally positive attitude against SM 89.3\% $(\mathrm{n}=536)$ and those with a negative attitude against SM amounted to $10.7 \%(\mathrm{n}=64)$. Considering specific attitude questions, $22.5 \%(\mathrm{n}=135)$ of respondents agreed that SM should be encouraged, $21.8 \%(n=131)$ believed that if the medication helped in the past it will help again and $19 \%$ $(n=114)$ believed that they would rather treat themselves than go to the nearest health facility (Table 6).

\section{Quality of Life of Respondents}

During the study, participants were asked for their current satisfaction level of quality of life with specific details on their relationship among family friends, colleagues, and others. They were also asked abouttheir achievement and accomplishment; career and profession; ability to cope with their day-to-day activities; financial satisfaction and their living condition in terms of housing. Participants' quality of life was also tested by requesting for the presence of social support ("edir" which is a local name for the gathering of people living in one area and supporting each other during a death in one's family, and ekub, which is a local name for a gathering of a small group of people to support each other through a contribution of money in a regular period and providing it to a member one at a time). The summary of the values obtained indicated that $79.7 \%(\mathrm{n}=478)$ were satisfied with their quality of life and 20.3\% (122) were not.

Table 6 Description of the Attitude of Respondents on Self-Medication (SM)

\begin{tabular}{|l|l|l|l|}
\hline Questions & \multicolumn{3}{l|}{ Level of Agreement } \\
\cline { 2 - 4 } & Agree (\%) & Neutral (\%) & Disagree (\%) \\
\hline Any medication can be used without seeing a health-care professional. & 14.2 & 20.7 & 65.2 \\
It is okay to share medicine with family or friends without it being prescribed. & 8.5 & 6 & 85.5 \\
SM should be encouraged. & 22.5 & 19.7 & 57.8 \\
If medication helped in the past it will help again. & 21.8 & 17.8 & 60.4 \\
Medication should be used at the sign of the first symptom. & 17.3 & 14.8 & 67.8 \\
Medicines that are nonprescribed/OTC cause no side effects. & 6.8 & 10 & 83.2 \\
Safety of nonprescribed medicines/OTC is well-known for all types of population. & 4.5 & 9.2 & 86.3 \\
I would rather treat myself than go to the nearest health facility. & 19 & 19 & 62 \\
Many medical problems can be treated with SM. & 8.7 & 19.5 & 71.8 \\
\hline
\end{tabular}




\section{Use of Nonprescribed Medicines}

It was found out that, $72.2 \%(\mathrm{n}=433)$ have ever experience of SM or prevalence in their lifetime which is a similar finding to the study carried out recently in Ethiopia ${ }^{37}$ that identified a $75.5 \%$ SM prevalence and Colombia ${ }^{38}$ where $77.5 \%$ of the sample had self-medicated at least once in their life. In addition, in this study, 214 respondents were identified to have used nonprescribed medicines in the last two months making the prevalence of the use of nonprescribed medicines $35.7 \%$.

As described in Tables 7-table 8, table 9 varied amount of influence of each of the socioeconomic characteristics (predisposing, enabling, and need factors) was established with the dependent variable during the bivariate analysis. Next, those variables that were statistically significant were included in the multivariable regression analysis to determine their predictor effect on the nonprescribed medicines among respondents.

The results of the analysis of the factors affecting the utilization of nonprescribed medicines among respondents are presented in Table 10.

All the 600 respondents were included in the analysis and the -2 log-likelihood was 130.671. The "pseudo" $\mathrm{R}$ estimate indicated that the model explained between $47.9 \%$ (Cox and Snell R squared) and 66.8\% (Nagelkerke R squared) of the variance in the utilization of nonprescribed medicines among the respondents.

In this model, age ( $p$-value $=0.039)$, occupation $(p$-value $=0.005), \quad$ knowledge $\quad(\mathrm{p}$-value $=0.002)$,attitudes (SM if the medication is at home ( $p$-value $=0.011)$, in all types of illnesses prefer SM ( $p$-value $=0.006)\}$ of predisposing factors were the independent variables that had statistically significant effect. In addition, quality of life satisfaction from social support (edir, association, ekub) ( $p$-value $=0.037$ ), quality of life from financial satisfaction ( $p$-value $=0.009)$ of enabling factors and illness in the past two months ( $p$-value $=0.000)$ from need factors of the were the independent variables that had statistically significant effect as predictors of utilization nonprescribed medicines (Table 10).

The analysis identified that the probability of using nonprescribed medicine was higher for the respondents in the age group (50-59) than (40-49) and (30-39) compared to the reference group (18-29). The odds, adjusted odds ratio (AOR) for the use were 5.809, 4.713, and 4.351 respectively. This positive effect of age toward the utilization of nonprescribed medicines corroborates the findings of a study conducted in urban Puducherry, India ${ }^{38}$ ( $p$-value $=0.006)$ and the case study of Kiambu County, Kenya. ${ }^{6}$ These studies identified that if the age of the person increases by unit she/he is 1.02054 times likely to self-medicate when all other variables are at reference levels with the effect being statistically significant.

The occupation professional was also indicated to be the major factor in the consumption of nonprescribed medicines compared to the reference group with marked significance $(\mathrm{AOR}=10.777, p$-value $=0.003)$ in the multivariable regression analysis. This finding resonates with the findings obtained in the study carried out in urban Puducherry, India ${ }^{39}$ with a statistically significant association ( $p$-value $=0.003)$ and that of Minia, Egypt ( $p$-value $=0.003){ }^{40}$ Those respondents who were ill during the past two months were found to be significantly selfmedicating as compared to those who were not ( $p$-value $=0.000)$. Respondents who have a practice of using nonprescribed medicine because the medicine is available at home were also identified to be a statistically significant predictor in their use of nonprescribed medicines $(\mathrm{AOR}=5.275, p$-value $=0.011)$.

Similarly, the regression model indicated that those respondents who provided a positive response towards preferring SM in all types of illnesses presented a significant effect on the use of nonprescribed medicines $(\mathrm{AOR}=5.214, p$-value $=0.006)$. Regarding the level of quality of social relationships (satisfaction with their social support, edir, association and ekub), those respondents with neutral responses were found to be lower in using nonprescribed medicines compared to the reference group which was dissatisfied with their quality of social relationship $(\mathrm{AOR}=0.100 p$-value $=0.037)$. On the contrary, those respondents with a satisfactory level of quality of life in terms of financial capabilities were identified to be strongly predicting the use of nonprescribed medicines $(\mathrm{AOR}=8.047, p$-value $=0.002)$.

The model indicated that those participants who were knowledgeable if all drugs cannot be given to nursing mothers were found to be statistically significant (AOR $=6.058, p$-value $=0.002$ ). Just as the effect observed in the bivariate analysis, the age group (50-59) was found to be the predictor of nonprescribed medicine in the multivariable regression analysis. On the contrary, the age group ( $>60)$ was not identified to be the predictor when analyzed in the multivariable regression analysis. 
Table 7 Association of Predisposing Factors with the Use of Nonprescribed Medicines $(n=600)$

\begin{tabular}{|c|c|c|c|c|c|c|c|c|}
\hline \multirow[t]{2}{*}{ Enabling Factors } & \multirow[t]{2}{*}{ B } & \multirow[t]{2}{*}{ SE } & \multirow[t]{2}{*}{ Wald } & \multirow[t]{2}{*}{ df } & \multirow[t]{2}{*}{ Sig. } & \multirow[t]{2}{*}{$\begin{array}{l}\operatorname{Exp}(B) / \\
\text { COR }\end{array}$} & \multicolumn{2}{|c|}{$\begin{array}{l}95 \% \mathrm{Cl} \text { for } \operatorname{Exp} \\
\text { (B) }\end{array}$} \\
\hline & & & & & & & Lower & Upper \\
\hline \multicolumn{9}{|l|}{ Age } \\
\hline 18-29 (reference) & & & 18.042 & 4 & 0.001 & & & \\
\hline $30-39$ & -0.122 & 0.250 & 0.239 & 1 & 0.625 & \multicolumn{3}{|c|}{$0.885(0.542-1.445)$} \\
\hline $40-49$ & -0.366 & 0.276 & 1.762 & I & 0.184 & \multicolumn{3}{|c|}{$0.693(0.404-1.191)$} \\
\hline $50-59$ & 0.620 & 0.292 & 4.506 & I & 0.034 & \multicolumn{3}{|c|}{$1.858(1.049-3.293)$} \\
\hline$>60$ & 0.566 & 0.277 & 4.194 & 1 & 0.041 & \multicolumn{3}{|c|}{$1.762(1.025-3.030)$} \\
\hline \multicolumn{9}{|l|}{ Employment status } \\
\hline Private employee (reference) & & & 12.269 & 6 & 0.056 & & & \\
\hline Government employee & -0.128 & 0.342 & 0.139 & 1 & 0.709 & \multicolumn{3}{|c|}{$0.880(0.450-1.721)$} \\
\hline Housewife & 0.025 & 0.258 & 0.009 & 1 & 0.924 & \multicolumn{3}{|c|}{$1.025(0.618-1.698)$} \\
\hline Self-employed & 0.000 & 0.368 & 0.000 & 1 & 1.000 & \multicolumn{3}{|c|}{$1.000(0.487-2.055)$} \\
\hline Student & 0.606 & 0.475 & 1.626 & I & 0.202 & \multicolumn{3}{|c|}{$1.833(0.722-4.654)$} \\
\hline Unemployed & 0.258 & 0.449 & 0.330 & I & 0.566 & \multicolumn{3}{|c|}{$1.294(0.537-3.119)$} \\
\hline Pensioner & 1.204 & 0.430 & 7.833 & 1 & 0.005 & \multicolumn{3}{|c|}{$3.333(1.435-7.746)$} \\
\hline \multicolumn{9}{|l|}{ Occupation } \\
\hline Unskilled laborer (reference) & & & 12.846 & 5 & 0.025 & & & \\
\hline Manager & -1.486 & 0.841 & 3.123 & 1 & 0.077 & \multicolumn{3}{|c|}{$0.226(0.044-1.176)$} \\
\hline Professional & 0.075 & 0.436 & 0.029 & I & 0.864 & $1.078(0.4$ & $8-2.535)$ & \\
\hline Clerical & -2.690 & 1.084 & 6.165 & I & 0.013 & $0.068(0.0$ & $8-0.567)$ & \\
\hline Sales and services & -0.218 & 0.473 & 0.212 & 1 & 0.645 & $0.804(0.3$ & (8-2.032) & \\
\hline Skilled laborer & -0.826 & 0.506 & 2.662 & 1 & 0.103 & $0.438(0.1$ & $2-1.181)$ & \\
\hline Marital status & & & & & & & & \\
\hline Unmarried (reference) & & & 10.700 & 3 & 0.013 & & & \\
\hline Married & 0.082 & 0.249 & 0.108 & 1 & 0.743 & $1.085(0.6$ & $36-1.768)$ & \\
\hline Divorced & 0.768 & 0.358 & 4.595 & 1 & 0.032 & $2.155(1.0$ & $8-4.349)$ & \\
\hline Widowed & 0.683 & 0.315 & 4.698 & 1 & 0.030 & $1.981(1.0$ & $8-3.675)$ & \\
\hline Educational status & & & & & & & & \\
\hline Postgraduate degree (reference) & & & 11.221 & 5 & 0.047 & & & \\
\hline No formal education & -0.482 & 0.237 & 4.158 & 1 & 0.041 & $0.617(0.3$ & $38-0.981)$ & \\
\hline Primary education & -0.532 & 0.254 & 4.372 & I & 0.037 & $0.588(0.3$ & 7-0.967) & \\
\hline High school & 0.053 & 0.282 & 0.035 & 1 & 0.851 & $1.054(0.6$ & $7-1.832)$ & \\
\hline Diploma & -0.546 & 0.347 & $2.47 I$ & 1 & 0.116 & $0.579(0.2$ & $3-1.144)$ & \\
\hline Degree & 1.391 & 1.168 & 1.417 & 1 & 0.234 & $4.018(0.4$ & $7-39.656)$ & \\
\hline Family status & & & & & & & & \\
\hline$<4$ inhabitants (reference) & & & 5.211 & 2 & 0.074 & & & \\
\hline $5-9$ inhabitants & 0.395 & 0.178 & 4.916 & I & 0.027 & $1.484(1.0$ & (7-2.103) & \\
\hline$>9$ inhabitants & -0.075 & 0.440 & 0.029 & I & 0.864 & $0.928(0.3$ & $2-2.196)$ & \\
\hline SM if the medication is available at home (Yes) (reference No) & 1.910 & 0.219 & 75.826 & I & 0.000 & $6.756(4.3$ & $5-10.386)$ & \\
\hline SM if you know someone who has taken it before (Yes) (reference No) & 1.548 & 0.183 & 71.336 & 1 & 0.000 & $4.702(3.2$ & $33-6.735)$ & \\
\hline SM if you have taken the medication previously (Yes) (reference No) & 1.503 & 0.190 & 62.553 & 1 & 0.000 & $4.496(3.0$ & $8-6.525)$ & \\
\hline $\begin{array}{l}\text { Recommend to someone who has similar symptom (Yes) (reference } \\
\text { No) }\end{array}$ & 1.399 & 0.203 & 47.681 & 1 & 0.000 & $4.05 I(2.7$ & $3-6.026)$ & \\
\hline In all types of illness prefer SM (Yes) (reference No) & 1.329 & 0.181 & 54.050 & I & 0.000 & $3.777(2.6$ & (0-5.382) & \\
\hline $\begin{array}{l}\text { Knowledge, how to store medicine (knowledgeable) } \\
\text { (not knowledgeable reference) }\end{array}$ & 0.405 & 0.190 & 4.525 & I & 0.033 & $0.667(0.4$ & ;9-0.969) & \\
\hline
\end{tabular}

(Continued) 
Table 7 (Continued).

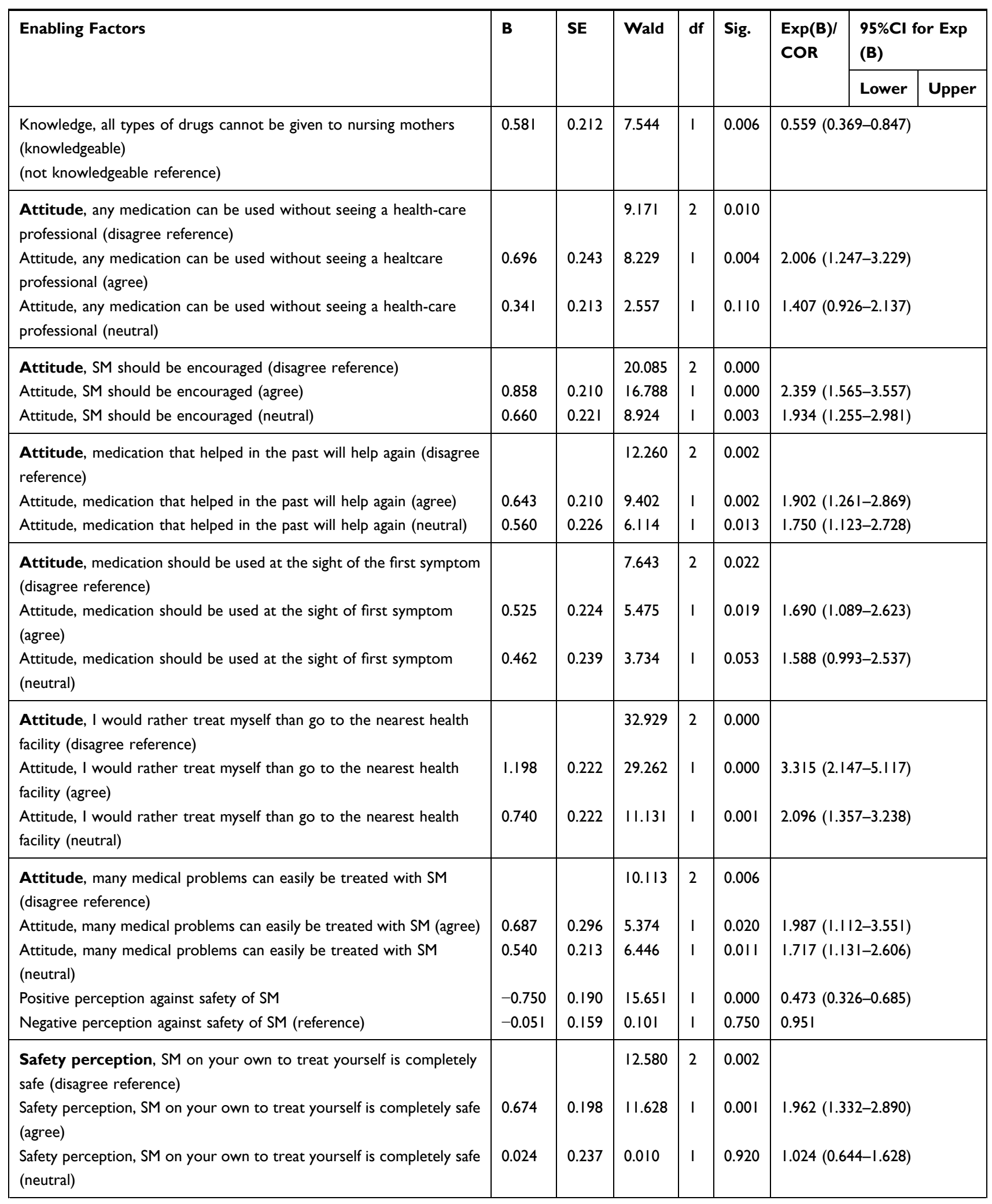

(Continued) 
Table 7 (Continued).

\begin{tabular}{|c|c|c|c|c|c|c|c|c|}
\hline \multirow[t]{2}{*}{ Enabling Factors } & \multirow[t]{2}{*}{ B } & \multirow[t]{2}{*}{ SE } & \multirow[t]{2}{*}{ Wald } & \multirow[t]{2}{*}{ df } & \multirow[t]{2}{*}{ Sig. } & \multirow[t]{2}{*}{$\begin{array}{l}\operatorname{Exp}(B) / \\
\text { COR }\end{array}$} & \multicolumn{2}{|c|}{$\begin{array}{l}\text { 95\%Cl for Exp } \\
\text { (B) }\end{array}$} \\
\hline & & & & & & & Lower & Upper \\
\hline $\begin{array}{l}\text { Safety perception, SM for family/friends is not dangerous (disagree } \\
\text { reference) }\end{array}$ & & & 11.567 & 2 & 0.003 & & & \\
\hline Safety perception, SM for family/friends is not dangerous (agree) & 0.630 & 0.315 & 3.996 & I & 0.046 & \multicolumn{3}{|c|}{$1.878(1.012-3.484)$} \\
\hline Safety perception, SM for family/friends is not dangerous (neutral) & 0.599 & 0.194 & 9.514 & I & 0.002 & \multicolumn{3}{|c|}{$1.820(1.244-2.662)$} \\
\hline $\begin{array}{l}\text { Safety perception, } S M \text { is safe when used with information from } \\
\text { family or friends (disagree reference) }\end{array}$ & & & $14.88 \mid$ & 2 & 0.001 & & & \\
\hline $\begin{array}{l}\text { Safety perception, } S M \text { is safe when used with information from family } \\
\text { or friends (agree) }\end{array}$ & 0.632 & 0.199 & 10.046 & I & 0.002 & \multicolumn{3}{|c|}{$1.88 \mathrm{I}(1.273-2.779)$} \\
\hline $\begin{array}{l}\text { Safety perception, SM is safe when used with information from family } \\
\text { or friends (neutral) }\end{array}$ & 0.719 & 0.237 & 9.243 & 1 & 0.002 & \multicolumn{3}{|c|}{$2.053(1.291-3.263)$} \\
\hline
\end{tabular}

Table 8 Association of Enabling Factors with the Use of Nonprescribed Medicines $(n=600)$

\begin{tabular}{|c|c|c|c|c|c|c|c|c|}
\hline \multirow[t]{2}{*}{ Enabling Factors } & \multirow[t]{2}{*}{ B } & \multirow[t]{2}{*}{ SE } & \multirow[t]{2}{*}{ Wald } & \multirow[t]{2}{*}{ df } & \multirow[t]{2}{*}{ Sig. } & \multirow[t]{2}{*}{$\begin{array}{l}\operatorname{Exp}(B) / \\
\text { COR }\end{array}$} & \multicolumn{2}{|c|}{$\begin{array}{l}\text { 95\%Cl for Exp } \\
\text { (B) }\end{array}$} \\
\hline & & & & & & & Lower & Upper \\
\hline $\begin{array}{l}\text { Quality of life, social support (edir) association and ekub } \\
\text { (not satisfied reference) }\end{array}$ & & & 10.380 & 2 & 0.006 & & & \\
\hline $\begin{array}{l}\text { Quality of life, social support (edir) association and ekub } \\
\text { (satisfied) }\end{array}$ & 0.783 & $0.4 \mid 4$ & 3.579 & 1 & 0.59 & \multicolumn{3}{|c|}{$2.188(0.972-4.925)$} \\
\hline Quality of life, Social support (edir) association and ekub (neutral) & 0.129 & 0.456 & 0.80 & I & 0.777 & \multicolumn{3}{|c|}{$1.138(0.465-2.783)$} \\
\hline Quality of life, financial satisfaction (not satisfied Reference) & & & 7.700 & 2 & 0.021 & \\
\hline Quality of life, financial satisfaction (satisfied) & -0.533 & 0.218 & 5.984 & 1 & 0.014 & \multicolumn{3}{|c|}{$0.587(0.383-0.899)$} \\
\hline Quality of life, financial satisfaction (neutral) & -0.579 & 0.229 & 6.371 & 1 & 0.012 & \multicolumn{3}{|c|}{$0.560(0.357-0.879)$} \\
\hline Income (highest reference) & & & 6.039 & 3 & 0.110 & \\
\hline Income (low) & 0.422 & 0.284 & 2.208 & I & 0.137 & \multicolumn{3}{|c|}{$1.525(0.874-2.662)$} \\
\hline Income (middle) & 0.619 & 0.306 & 4.088 & I & 0.043 & \multicolumn{3}{|c|}{$1.858(1.019-3.386)$} \\
\hline Income (high) & 0.078 & 0.347 & 0.050 & I & 0.822 & \multicolumn{3}{|c|}{$1.081(0.548-2.132)$} \\
\hline
\end{tabular}

Table 9 Association of Need Factors with the Use of Nonprescribed Medicines $(n=600)$

\begin{tabular}{|c|c|c|c|c|c|c|c|c|}
\hline \multirow[t]{2}{*}{ Need Factors } & \multirow[t]{2}{*}{ B } & \multirow[t]{2}{*}{ SE } & \multirow[t]{2}{*}{ Wald } & \multirow[t]{2}{*}{ df } & \multirow[t]{2}{*}{ Sig. } & \multirow[t]{2}{*}{$\operatorname{Exp}(B) C O R$} & \multicolumn{2}{|c|}{$95 \% \mathrm{Cl}$ for $\operatorname{Exp}(\mathrm{B})$} \\
\hline & & & & & & & Lower & Upper \\
\hline Illness in the past two months (Yes) (No reference) & 2.059 & 0.194 & 112.664 & I & 0.000 & \multicolumn{3}{|c|}{$7.839(5.360-11.465)$} \\
\hline Perceived Health status Poor (reference) & & & 31.165 & 3 & 0.000 & & & \\
\hline Very good & 0.123 & 0.214 & 0.330 & I & 0.566 & \multicolumn{3}{|c|}{$1.131(0.744-1.719)$} \\
\hline Good & 1.014 & 0.220 & 21.331 & I & 0.000 & \multicolumn{3}{|c|}{$2.757(1.793-4.240)$} \\
\hline Average & 1.515 & 0.438 & 11.951 & I & 0.001 & \multicolumn{3}{|c|}{$4.55 \mathrm{I}(1.927-10.746)$} \\
\hline
\end{tabular}


Table 10 Logistic Regression Model of Nonprescribed Medicines Use $(n=600)$

\begin{tabular}{|c|c|c|c|c|c|c|c|c|}
\hline & \multicolumn{2}{|l|}{ COR } & \multicolumn{6}{|l|}{ AOR } \\
\hline & $p$-value & $\operatorname{Exp}(B)(95 \% C l)$ & B & SE & Wald & df & pvalue & $\operatorname{Exp}(B)(95 \% C l)$ \\
\hline Age 18-29 (reference) & 0.001 & & & & 10.109 & 4 & 0.039 & \\
\hline $30-39$ & 0.625 & $0.885(0.542-1.445)$ & $1.47 \mid$ & 0.634 & 5.385 & 1 & 0.020 & $4.351(1.257-15.067)$ \\
\hline $40-49$ & 0.184 & $0.693(0.404-1.191)$ & 1.550 & 0.783 & 3.923 & 1 & 0.048 & $4.713(1.016-21.857)$ \\
\hline $50-59$ & 0.034 & $1.858(1.049-3.293)$ & 1.759 & $0.88 I$ & 3.984 & 1 & 0.046 & $5.809(1.032-32.685)$ \\
\hline$>60$ & 0.041 & $1.762(1.025-3.030)$ & -0.850 & 1.142 & 0.554 & 1 & 0.457 & $0.427(0.046-4.008)$ \\
\hline $\begin{array}{l}\text { Occupation (unskilled } \\
\text { laborer=reference) }\end{array}$ & 0.025 & & & & 16.911 & 5 & 0.005 & \\
\hline Manager & 0.077 & $0.226(0.044-1.176)$ & -1.510 & 1.306 & 1.336 & 1 & 0.248 & 0.221 (0.017-2.859) \\
\hline Professional & 0.864 & $1.078(0.458-2.535)$ & 2.377 & 0.806 & 8.695 & 1 & 0.003 & 10.777 (2.219-52.327) \\
\hline Clerical job & 0.013 & $0.068(0.008-0.567)$ & -1.627 & 1.456 & 1.248 & 1 & 0.264 & $0.197(0.011-3.414$ \\
\hline Sales and service & 0.645 & $0.804(0.318-2.032)$ & 1.536 & 0.815 & 3.553 & 1 & 0.059 & $4.648(0.94 I-22.963)$ \\
\hline Skilled laborer & 0.103 & $0.438(0.162-1.181)$ & 1.181 & 0.826 & 2.048 & 1 & 0.152 & $3.259(0.646-16.437$ \\
\hline $\begin{array}{l}\text { Illness in the past two months (Yes) } \\
\text { (No=reference) }\end{array}$ & 0.000 & $7.839(5.360-11.465)$ & 4.129 & 0.660 & 39.100 & 1 & 0.000 & $62.134(17.030-226.696)$ \\
\hline $\begin{array}{l}\text { SM if the medication is available at } \\
\text { home (Yes) }(\mathrm{No}=\text { reference) }\end{array}$ & 0.000 & $6.756(4.395-10.386)$ & 1.663 & 0.656 & 6.431 & 1 & 0.011 & $5.275(1.459-19.073)$ \\
\hline $\begin{array}{l}\text { In all types of illness prefer SM (Yes) } \\
\text { (No=reference) }\end{array}$ & 0.000 & $3.777(2.650-5.382)$ & 1.651 & 0.598 & 7.635 & 1 & 0.006 & $5.214(1.616-16.825)$ \\
\hline $\begin{array}{l}\text { Quality of life, social support (edir) } \\
\text { association and ekub } \\
\text { (not satisfied reference) }\end{array}$ & & & 10.380 & 2 & 0.006 & & & \\
\hline $\begin{array}{l}\text { Quality of life, social support edir } \\
\text { association ekub (neutral) } \\
\text { (dissatisfied=reference) }\end{array}$ & 0.777 & I.I38 (0.465-2.783) & -2.305 & 1.103 & 4.371 & I & 0.037 & $0.100(0.011-0.866)$ \\
\hline $\begin{array}{l}\text { Quality of life, financial satisfaction } \\
\text { (dissatisfied=reference) }\end{array}$ & & & & & 9.325 & 2 & 0.009 & \\
\hline $\begin{array}{l}\text { Quality of life, financial satisfaction } \\
\text { (satisfied) }\end{array}$ & 0.014 & $0.587(0.383-0.899)$ & 2.085 & 0.704 & 8.776 & 1 & 0.003 & $8.047(2.025-31.977)$ \\
\hline $\begin{array}{l}\text { Knowledge, all types of drugs cannot } \\
\text { be given to nursing mothers } \\
\text { (knowledgeable) (not } \\
\text { knowledgeable=reference) }\end{array}$ & 0.006 & $0.559(0.369-0.847)$ & 1.801 & 0.584 & 9.513 & I & 0.002 & $6.058(1.928-19.030)$ \\
\hline Constant & & & -8.232 & 1.497 & 30.247 & 1 & 0.000 & 0.000 \\
\hline
\end{tabular}

During the bivariate analysis, the independent effect of the variables; marital status, educational status, SM if you know someone who has taken it before, SM if you have taken the medication previously, recommended to someone who has similar symptoms, knowledge on how to store medicines, attitude any medication can be used without seeing a health-care professional, SM should be encouraged, medication that helped in the past will help again, medication should be used at the site of the first symptom, I would rather treat myself than go to the nearest health care facility, many medical problems can easily be treated with SM, safety perceptions, income, and perceived health status were not observed to be significant when they were analyzed controlling for the effect of other independent variables in the regression analysis.

Regarding the relation to the overall fit of the model, the result of the analysis indicated that the null hypothesis $\left(\mathrm{H}_{0}\right)$ that the predictors did not have any effect on the utilization of nonprescribed medicines was rejected (chisquared $=139.077, \mathrm{df}=20$, and $p$-value $=0.000$, overall correctness of prediction $=85.9 \%$ ). On the contrary, the respondents' age, occupation, knowledge, attitudes, SM if the medication is at home, in all types of illnesses prefer SM, quality of life satisfaction from social support, quality of life from financial satisfaction, illness in the past two 
months were the predictors of utilization of nonprescribed medicines (Table 10).

\section{Conclusions and Recommendations}

This study concluded that selected socioeconomic factors of individuals in Yeka, Addis Ababa, Ethiopia were predictors of nonprescribed medicines use (model $p$-value $=0.000)$. These factors were age, occupation, knowledge, and attitude as predisposing factors; quality of life satisfaction from social support (edir, association, ekub) and quality of life from financial satisfaction of enabling factors, and illness in the past two months from need factors of the respondents in Yeka, Addis Ababa, Ethiopia.

As obtained from the study, one-third of the population had a practice of nonprescribed medicine consumption in the last two months, two-thirds had an ever experience of nonprescribed medicine use and additionally, individuals have demonstrated their intention to self-medicate when experiencing different ailments. Although the positive aspect of SM in reducing the health service burden needs to be encouraged, it is necessary to strategize for appropriate SM. Therefore, this calls for action to minimize the unnecessary medicine-related harm that may be caused owing to inappropriate use and wastage of limited resources.

Recommendations for the awareness creation programs designed need to focus on changing the knowledge attitude and perception of the specific groups identified to have a predictive effect on the use of nonprescribed medicines. The tailored actions need to focus on age groups (50-59), (40-49) and (30-39); the occupation professionals; the practice of SM if the medicine is available at home; the knowledge that not all drugs can be given to nursing mothers; quality of life satisfaction obtained from social support groups, quality of life obtained from financial satisfaction and illness in the past two months.

Recommendations for the regulatory system are as follows.

- Enforce regulations and guidelines of good dispensing and good counseling practices so that healthcare professionals who are providing nonprescribed medicines at various health sectors can have sufficient knowledge to implement them.

- Revise the over the counter OTC/nonprescribed medicines list that is currently available in the country.
- Establish a continuing education mechanism for the effective utilization of pharmacy professionals towards providing proper diagnosis, treatment, and referral of patients from community drug outlets.

- Establish a special drug consultation service that would be provided by pharmacy professionals to enable consumers to benefit from professional drug consulting services.

- Establish and implement a behind the counter/BTC medication system where certain selected groups of OTC medications are dispensed to the public through a trained and qualified pharmacy professional. The selected nonprescribed medicines will be provided with the appropriate initial assessment and screening, medication reviews, counseling, and medication monitoring to ensure the safety appropriateness and effectiveness of the use of nonprescribed medicines by the public.

- Establish a pharmacy take-back programs where leftover medicines available at home are submitted to pharmacies by the public so that they could be disposed of appropriately.

\section{Limitations of the Study}

As the study was conducted at a community level, the individuals' self-evaluation of illness severity and the associated need to seek treatment was not studied. In addition, as the chosen recall period is two months, there was an effect of recall bias. The latter was resolved by the strong effort and efficiency of the interviewing capacity of the data collectors.

\section{Acknowledgment}

The author would like to acknowledge Professor Tshweneagae Gloria from UNISA for her invaluable support throughout the whole study, the data collectors for their strong and ethical work, and the study participants who have made the research possible through their cooperation and involvement in providing the necessary data.

\section{Disclosure}

The author reports no conflicts of interest in this work.

\section{References}

1. Artiga S, Hinton E. Beyond Healthcare: The Role of Social Determinants in Promoting Health and Health Equity. Henry J Kaiser Family foundation; 2018:1-13. 
2. Marmot M. The health gap: doctors and the social determinants of health. Scand J Public Health. 2017;45:686-693. doi:10.1177/ 1403494817717448

3. Donkin A, Goldblatt P, Allen J, Nathanson V, Marmot M. Global action on the social determinants of health. BMJ Glob Health. 2017;3:1-7.

4. Ayanwale MB, Okafor IP, Odukoya OO. Self-medication among rural residents in Lagos, Nigeria. $J$ Med Tropics. 2017;19:65-71. doi:10.4103/jomt.jomt_51_16

5. Bakhtiar K, Bastami F, Almasian M, Sharafkhani N. The psychological determinants of self-medication among the elderly: an explanation based on the health belief model. Elderly Health J. 2017;3 (2):59-66.

6. Mageto T, Zablon A. Modeling self-medication risk factors. A case study of Kiambu County, Kenya. Am J Theor Appl Stat. 2018;7 (2):58-66. doi:10.11648/j.ajtas.20180702.12

7. Aziz MM, Masood I, Yousaf M, Saleem H, Ye D, Fang Y. Pattern of medication selling and self-medication practices: a study from Punjab, Pakistan. PLoSONE. 2018;13(3):1-12. doi:10.1371/journal. pone. 0194240

8. Lei X, Jiang H, Liu C, Ferrier A, Mugavin J. Self-medication practice and associated factorsamong residents in Wuhan, China. Int J Environ Res Pub Health. 2018;15:68. doi:10.3390/ijerph15010068

9. Rahmawati R, Bajorek BV. Self-medication among people living with hypertension: a review. Fam Pract. 2018;34(2):147-153.

10. Alghadeer S, Aljuaydi K, Babelghaith S, Alhammad A, Alarifi MN. Self-medication with antibiotics in Saudi Arabia. Saudi Pharm J. 2018;26:719-724. doi:10.1016/j.jsps.2018.02.018

11. Alhomoud F, Aljamea Z, Almahasnah R, Alkhalifah K, Basalelah L, Alhomoud FK. Self-medication and self-prescription with antibiotics in the Middle East - do they really happen? A systematic review of the prevalence, possible reasons, and outcomes. Int $J$ Infect Dis. 2017;57:3-12. doi:10.1016/j.ijid.2017.01.014

12. Dönmez S, Güngör K, Pinar G. Knowledge, attitude, and practice of self-medication with antibiotics among nursing students. Int J Pharmacol. 2017;14:136-143. doi:10.3923/ijp.2018.136.143

13. Kajeguka DC, Moses EA. Self-medication practices and predictors for self-medication with antibiotics and antimalarials among the community in Mbeya City, Tanzania. Tanzan J Health Res. 2017;19 (4): $1-10$

14. Moise K, Bernard JJ, Henrys JH. Evaluation of antibiotic self-medication among outpatients of the state university hospital of Port-Au-Prince, Haiti: a cross-sectional study. Pan Afr Med J. 2017;28(4):1-4. doi:10.11604/pamj.2017.28.4.12589

15. Shamsudeen SM, Priya RS, Govindarajan P, Sujatha J, Muruganandhan K, Manikandan R. Self-medication with antibiotics: a knowledge, attitude, and practice appraisal of 610 dental patients in Chennai, India, from 2016 to 2017. $J$ Edu Health Promot. 2018;7:66-70. doi:10.4103/jehp.jehp_143_17

16. Mohammed G. Self-medication: A serious threat to society. Lupine Online Journal of Nursing and Healthcare India. 2018;1(1):1-3.

17. Kovačević I, Kogler VM, Turković TM, Dunkić LF, Ivanec Z, Petek D. Self-care of chronic musculoskeletal pain-experiences and attitudes of patients and health care providers. Croatia. BMC Musculoskelet Disord. 2018;19(76):1-10. doi:10.1186/s12891-018-1997-7

18. Noone J, Blanchette CM. The value of self-medication: summary of existing evidence. J Med Econ. 2017;1-25.

19. AlRaddadi KK, Barakeh RM, AlRefaie SM, et al. Determinants of self-medication among undergraduate students at King Saud University: knowledge, attitude and practice. $J$ Health Specialities. 2017;5:95-101. doi:10.4103/2468-6360.205078

20. Botyar M, Kashanian M, Rezaei Z, et al. A comparison of the frequency, risk factors, and type of self-medication in pregnant and non-pregnant women presenting to Shahid Akbar Abadi Teaching Hospital in Tehran. J Family Med Primary Care. 2018;7:124-129. doi:10.4103/jfmpc.jfmpc_227_17
21. Ezzatabadi MR, Rafiei S, Shafiei M, et al. Self-medication and contributing factors: a questionnaire survey among Iranian households. Bali Med J. 2016;5(3):376-380.

22. Gebrekirstos NH, Workneh BD, Gebregiorgis YS, et al. Nonprescribed antimicrobial use and associated factors among customers in drug retail outlet in Central Zone of Tigray, northern Ethiopia: a cross-sectional study. Antimicrob Resist Infect Control. 2017;6:70. doi:10.1186/s13756-017-0227-7

23. Hoai NT, Dhang D. The determinants of self-medication: evidence from urban Vietnam. Soc Work Health Care. 2017;56(4):260-282. doi:10.1080/00981389.2016.1265632

24. Lee C-H, Chang F-C, Hsu S-D, Chi H-Y, Huang L-J, Yeh M-K. Inappropriate self-medication among adolescents and its association with lower medication literacy and substance use. PLoS One. 2017;12(12):e0189199. doi:10.1371/journal.pone.0189199

25. Pons EDS, Knauth DR, Vigo Â, Mengue SS. Predisposing factors to the practice of self-medication in Brazil: results from the national survey on access, use, and promotion of rational use of medicines (PNAUM). PLoS One. 2017;12(12):1-12. doi:10.1371/journal. pone.0189098

26. Jerez-Roig J, Medeiros LF, Silva VA, et al. Prevalence of self-medication and associated factors in an elderly population: a systematic review. Drugs Aging. 2014;31:883-896. doi:10.1007/ s40266-014-0217-x

27. Shaghaghi A, Asadi M, Allahverdipour H. Predictors of self-medication behavior: a systematic review. Iran J Pub Health. 2014;43:136-146.

28. Zhao Y, Ma S. Observations on the prevalence, characteristics, and effects of self-treatment. Front Public Health. 2016;4:2-8. doi:10.3389/fpubh.2016.00069

29. Beyene KGM, Beza SW. Self-medication practice and associated factors among pregnant women in Addis Ababa, Ethiopia. Trop Med Health. 2018;46:101-114. doi:10.1186/s41182-0180091-z

30. Beyene A, Getachew E, Doboch A, Poulos E, Abdurahman K, Alebachew M. Knowledge, attitude, and practice of self-medication among pharmacy students of Rift Valley University, Abichu Campus, Addis Ababa, Ethiopia. J Health Med Informat. 2017;8:269. doi:10.4172/2157-7420.1000269

31. Ayalew MB. Self-medication practice in Ethiopia: a systematic review. Patient Prefer Adherence. 2017;11:401-413. doi:10.2147/ PPA.S131496

32. Taherdoost H. Validity and reliability of the research instrument: How to test the validation of a questionnaire/survey in a research. International Journal of Academic Research in Managment. 2016;5 (3):28-36.

33. Etikan I, Bala K. Sampling and Sampling Methods. Biom Biost Inter J. 2017;5(6):1-3.

34. Kothari CR, Garg G. Research Methodology Methods and Techniques. Chapter 3 Research Design. 3rd ed. India: New Age International Publishers; 2014.

35. Krithikadatta J. Normal distribution. J Conserv Dent. 2014;17:96-97. doi:10.4103/0972-0707.124171

36. Andersen RM, Davidson PL, Baumeister SE. Improving access to care in America: individual and contextual indicators. In: Changing the US Health Care System: Key Issues in Health Services Policy and Management. New York: Roputellege; 2014.

37. Shafie M, Eyasu M, Muzeyin K, Worku Y, Martõ̂̂n-AragoÂn S. Prevalence and determinants of self-medication practice among selectedhouseholds in Addis Ababa community. PLoS One. 2018;13 (3):1-20. doi:10.1371/journal.pone.0194122

38. Machado-Alba JE, Echeverri-Cataño LF, Londoño-Builes MJ, Moreno-Gutierrez PA, Ochoa-Orozco SA, Ruiz-Villa JO. Social cultural and economic factors associated with Self-medication. Biomedica. 2014;34(4):580-588. 
39. Selvaraj K, Kumar GS, Ramalingam A. Prevalence of self-medication practices and its associated factors in Urban Puducherry, India. Perspect Clin Res. 2014;5(1):32-36. doi:10.4103/2229-3485.124569
40. Ghazawy ER, Hassan EE, Mohamed EE, Emam SA. Self-medication among Adults in Minia, Egypt: a cross sectional community-based study. Health. 2017;9:883-895. doi:10.4236/health.2017.96063

\section{Publish your work in this journal}

Patient Preference and Adherence is an international, peer-reviewed, open access journal that focusing on the growing importance of patient preference and adherence throughout the therapeutic continuum. Patient satisfaction, acceptability, quality of life, compliance, persistence and their role in developing new therapeutic modalities and compounds to optimize clinical outcomes for existing disease states are major areas of interest for the journal. This journal has been accepted for indexing on PubMed Central. The manuscript management system is completely online and includes a very quick and fair peer-review system, which is all easy to use. Visit http:// www.dovepress.com/testimonials.php to read real quotes from published authors. 